\title{
A case of idiopathic granulomatous hypophysitis
}

\author{
Nilufer Ozdemir Kutbay, ${ }^{1}$ Mustafa Berker, ${ }^{2}$ Figen Soylemezoglu, ${ }^{3}$ \\ Hatice Ozisik, ${ }^{4}$ Banu Sarer Yurekli ${ }^{4}$
}

${ }^{1}$ University of Health Sciences Gazi Yasargil Education and Training Hospital, Division of Endocrinology, Diyarbakır,
Turkey; ${ }^{2}$ Acibadem Hospital, Department of Neurosurgery, Ankara, Turkey; ${ }^{3}$ Hacettepe University, Faculty of Medicine,
Pathology Department, Ankara, Turkey; ${ }^{4}$ Ege University, Faculty of Medicine, Endocrinology Department, Izmir, Turkey

Dear Sir,

Hypophysitis is a rare disease of the pituitary gland whose incidence is 1 case per 9 million people per year. ${ }^{1}$ Hypophysitis, which can be categorized as primary (idiopathic) hypophysitis and secondary hypophysitis, may develop through systemic inflammatory disorders such as tuberculosis, Wegener's granulomatosis and sarcoidosis. ${ }^{2}$ Based on histologic features there are two main types of hypophysitis: lymphocytic and granulomatous. Three rare forms have been described, namely IgG4-related hypophysitis, necrotizing hypophysitis and mixed forms. ${ }^{3}$ Granulomatous hypophysitis, first described in 1917 by Simmonds, ${ }^{4}$ has an incidence of 1 in 10 million and constitutes less than $1 \%$ of all pituitary disorders. ${ }^{5}$ Unlike lymphocytic hypophysitis, there is no sex preference. The mean age of diagnosis is $20 \mathrm{yr}$ for females and $50 \mathrm{yr}$ for males. This disorder is characterized by necrotizing granulomas that are formed by histiocytes and plasma cells surrounding

Key words: Idiopathic granulomatous hypophysitis, Magnetic resonance imaging, Pituitary adenomas

Address for correspondence:

Nilufer Ozdemir Kutbay, University of Health Sciences Gazi Yasargil Education and Training Hospital, Division of Endocrinology, Diyarbakır, Turkey; Tel.: +90 505524 2989, Fax: +90 232388 1115, E-mail: nozdemirkutbay@hotmail.com Received:10-10-2017, Accepted:12-10-2017 areas of necrosis. ${ }^{6}$ It is easily initially diagnosed as a pituitary adenoma, this based on nonspecific radiological features. We would like to report a rare case of idiopathic granulomatous hypophysitis presenting as a sellar mass and associated with hypopituitarism.

A 34-year-old male visited the endocrine clinic complaining of headache, fatigue and loss of libido. On physical examination his blood pressure was $120 / 70$ $\mathrm{mmHg}$ and his pulse rate was $64 \mathrm{beat} / \mathrm{min}$. Central obesity was present. The results of his hormone tests were as follows: TSH: $1.27 \mu \mathrm{IU} / \mathrm{ml}$, fT4: $0.582 \mathrm{ng} / \mathrm{dl}$, fT3: $1.88 \mathrm{pg} / \mathrm{ml}$, ACTH: $14.8 \mathrm{pg} / \mathrm{ml}$, cortisol: $9.05 \mathrm{ug} /$ dl, LH: $0,81 \mathrm{mIU} / \mathrm{ml}, \mathrm{FSH}: 0.97 \mathrm{mIU} / \mathrm{ml}$, prolactin: 22.23ng/ml, GH: 0.086ng/ml, IGF-1: 98 (115-307) $\mathrm{ng} / \mathrm{ml}$. His urine density was 1013 . After the detection of hypopituitarism, a hypophysis magnetic resonance imaging (MRI) was requested. The MRI showed a macroadenoma located in the adenohypophysis. The tumor, measuring $15 \times 9 \times 10 \mathrm{~mm}$, had pushed the normal parenchyma inferiorly pressing it into a tape-like form and the infundibulum slightly towards the superiorly (Figure 1). The patient first received steroid treatment followed by thyroid hormone replacement treatment and was referred to the neurosurgery department. A total adenoma excision was performed using the endoscopic endonasal transsphenoidal technique. The pathology test result revealed lymphoplasmacytic cell infiltration that had extensively damaged the adenohypophysis and non-necrotizing granuloma containing Langhanstype multinucleated giant cells. Gomori metanamin silver, periodic acid-Schiff and asidoresistant bacilli 


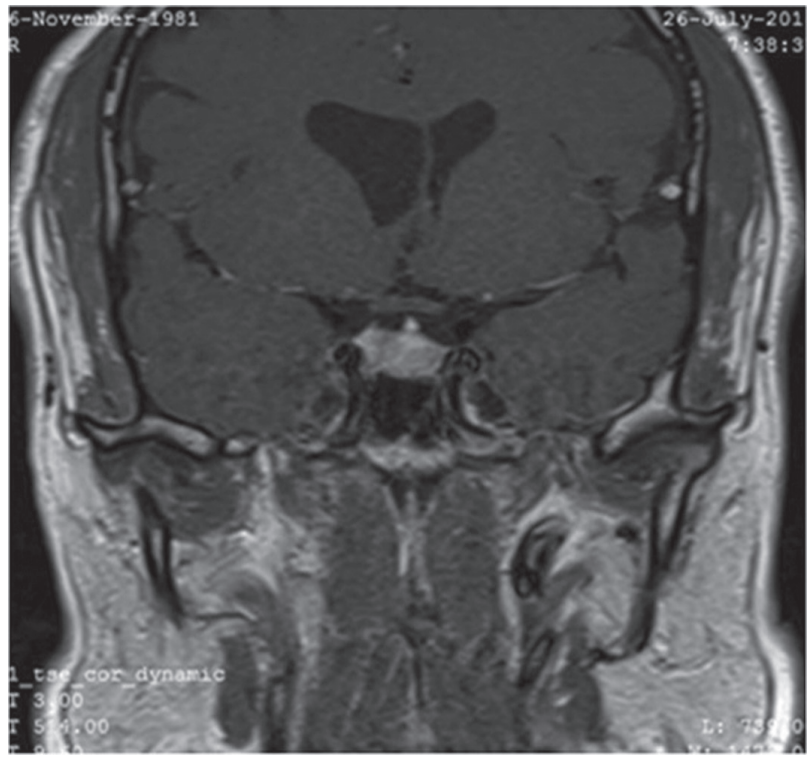

Figure 1. The MRI showed a macroadenoma located in adenohypophysis. The tumor, $15 \times 9 \times 10 \mathrm{~mm}$, has pushed the normal parenhyma inferiorly, pressing it into a tape-like and the infundibulum slightly towards syperiorly.

specific organisms were not observed. The pathological diagnosis was determined as granulomatous hypophysitis. The patient is on hydrocortisone $20 \mathrm{mg} /$ day and levothyroxine $75 \mathrm{mcg}$ /day and is receiving testosterone replacement every 3 weeks.

The clinical appearance of hypophysitis may mimic that of a pituitary adenoma. ${ }^{7}$ It includes headache, nausea, fatigue, hypopituitarism and diabetes insipidus. If there is mass effect on the optic chiasm vision may be distorted, usually with a typical bitemporal hemianopsia, while if the cavernous sinus is affected patients may have diplopia. Granulomatous hypophysitis is a very rare pituitary condition that is difficult to diagnose before surgery. The diagnosis of idiopathic granulomatous hypophysitis (IGH) is made following exclusion of secondary causes. ${ }^{8,9}$

MRI-specific information on IGH is sparsely reported in the literature, with pituitary enlargement being the most common feature. Contrast enhancement and pituitary stalk thickening can also be seen. Clinically and radiologically, IGH is a rare sellar structure that can be easily misdiagnosed as a pituitary adenoma. ${ }^{10}$

There is strong evidence in the published literature that anti-pituitary autoantibodies most probably play a role in the pathogenesis of autoimmune pituitary disorders. ${ }^{11}$

In conclusion, hypophysitis is a heterogeneous group of inflammatory conditions involving the pituitary gland. Idiopathic granulomatous hypophysitis is a very rare hypophyseal condition that is difficult to diagnose before surgery. The diagnosis of idiopathic granulomatous hypophysitis is made after excluding secondary causes. Despite medical treatment of the majority of suspicious cases, an increase in the size of the gland and symptoms associated with mass effect may lead to surgical intervention and gland resection.

\section{CONFLICT OF INTEREST}

The author does not have any conflict of interest.

\section{REFERENCES}

1. Buxton N, Robertson I, 2001 Lymphocytic and granulocytic hypophysitis: a single centre experience. Br J Neurosurg J 15: 242-246.

2. Goyal M, Kucharczyk W, Keystone E, 2000 Granulomatous hypophysitis due to Wegener's granulomatosis. AJNR 21: 1466-1469.

3. Caturegli P, Newschaffer C, Olivi A, et al, 2005 Autoimmune hypophysitis. Endocr Rev 26: 599-614.

4. Simmonds M 1917 Über das Vorkommen von Riesenzelle in der Hypophyse. Virchows Arch 223: 281-290.

5. Sautner D, Saeger W, Ludecke DK, Jansen V, Puchner MJA, 1995 Hypophysitis in surgical and autoptical specimens. Acta Neuropathol (Berlin) 90: 637-644.

6. Asa SL 1998 Tumors of the pituitary gland, third series, fascicle 22. Washington, DC: Armed Forces Institute of Pathology.

7. Gutenberg A, Landek-Salgado M, Tzou S-C et al, 2009 Autoimmune hypophysitis: expanding the differential diagnosis to CTLA-4 blockade. Expert Rev Endocrinol Metab 4: 681-698.

8. Supler ML, Mickle JP, 1992 Lymphocytic hypophysitis: Report of a case in a man with cavernous sinus involvement. Surg Neurol 37: 472-476.

9. Katzman GL, Langford CA, Sneller CM et al, 1999 Pituitary involvement by Wegener's granulomatosis: A report of two cases. Am J Neuroradiol 20: 519-523.

10. Xiangyi Kong, Renzhi Wang, Yi Yang, et al, 2015 Idiopathic Granulomatous Hypophysitis Mimicking Pituitary Abscess. Medicine (Baltimore) 94: e1099.

11. Hashimoto KI, Yamakita N, Ikeda T, et al, 2006 Longitudinal study of patients with idiopathic isolated TSH deficiency: possible progression of pituitary dysfunction in lymphocytic adenohypophysitis. Endocr J 53: 593-601. 